\title{
Discussion on Domestic Universities Construction of Digital Teaching Platform
}

\author{
a Jiancai Wang, ${ }^{\mathrm{b}}$ Hua Liang \\ ${ }^{a, b}$ Information Network Center Heilongjiang Institute of Science and Technology Harbin, China
}

\begin{abstract}
With the rise of Digital Campus 2.0, the construction of digital teaching environment based on multimedia technology, network technology and modern education technology, has gradually become the mainstream of domestic higher education. According to the educational features of colleges and universities, the digital teaching system accessible to spread over should be created in the base of summing up former experiences. This paper points out the existent problems in recent construction process and proposes specific solutions and aims of this construction. Furthermore, it analyzes the main contents of the environment construction, resources construction, team construction and mechanism construction of digital teaching platform.
\end{abstract}

Index Terms: digital Campus 2.0; network technology; digital teaching platform

(C) 2012 Published by MECS Publisher. Selection and/or peer review under responsibility of the International Conference on E-Business System and Education Technology

\section{Introduction}

With the spread and popularization of information technology, LAN is established and a lot of MIS is developed for daily management. With the development of educational informationization, the construction and effective use of digital teaching platform attracts educators' attention more and more. Facing a large number of information resources, how to understand the concept of a new construction and application of resources, how to construct and apply resources in new ideas and methods, how to continue reforming and innovation, how to seek a breakthrough and a new growth point to catch the tide of educational informationization and meet the needs of the times [1]. Fostering compound talents with information literacy and a higher capacity of innovation is our urgent problems. In response to the construction of the digital teaching platform of Heilongjiang Institute of Science and Technology, this paper discusses the construction of digital teaching platform.

\section{Main problems}

The construction of digital teaching environment has been carried out by many colleges and universities

Corresponding author:

E-mail address: ${ }^{\mathrm{a}}$ wangjiancai1@eyou.com 
consciously or not. As the infrastructure of educational informationization, the digital teaching environment has not been paid enough attention. There are many problems to be solved, including lack of awareness, the imbalance of digital quality between teachers and students and deficiency of resources integration, etc. On one hand, many colleges and universities assume educational informationization has a long way to go. They do not take digital teaching environment as a realistic task, with lack of the importance and emergency of digital teaching environment. On the other hand, some universities are blind to follow up in the process of digital construction. Without an overall scheme and criteria of construction, the equipment purchase is wasted and the construction of software environment is neglected, especially human factors. It causes great waste and affects the overall process of the construction.

Meanwhile, there is a situation that teachers are not adaptable to the environment and students are not competent for digital learning in real practice.

\section{Basic content of digital teaching environment}

With the application of information technology, we are approaching the age of 4A (That is Anyone, Anywhere, Anytime on Anything) [2]. However, the problems discussed above set the obstacles for sharing and high efficiency of teaching resource and cause amazing waste. Considering the possibility of "information isolated island" by making a sole teaching system, colleges and universities should review the experiences and think over their own educational features first, and then construct an "integrated digital platform for both teaching and learning. A digital teaching system accessible to spread over is created to promote the construction of digital teaching environment on campus. Meanwhile, we should enhance relative aspects in humanity, policy and system construction as well. It can be interpreted as a portal to integrate the application and provide humanization service for a single access point; an evaluation responsible for evaluating teachers and students within the teaching platform; a management, which manages teachers and students in the overall teaching environment; and $\mathrm{N}$ applications, including the collection, processing and application of information in each teaching system. Fig. 1 illustrates the composition.

\section{4. construction scheme}

Drawing on the useful experiences of our college in the process of constructing digital teaching platform, the above goals can be achieved. With the good experiences of our university, the environment construction includes resource construction, team construction and mechanism construction.

\section{1 Construction of Digital Environment}

Depending on campus network, the construction of digital environment is the base of digital teaching platform. It comprises the following components: high-performance server, massive storage system technology, secure backup, high-speed network switches, dedicated firewall, core system software and an application development platform for database, portal system, authentication system and middleware system [3]. Data center is a platform for information processing to realize integrated data, integrated equipment and integrated application. It also provides basic, shared and unified information. Through the data center, the application system, storage system and its structure model attached to each of the independent servers can be changed into centralized, large-scale, cheap, easily-managed, highly shared platform for information processing, storage and safety backup. Distributed data can be centralized processing and storage management. It focuses on integration of resources, optimization of resources, improves system efficiency and application level, to make a basis for the establishment of super-computing systems, network computing and development of digital teaching and research. It is a complex system with hard environment and soft environment. Hardware environment refers to hardware facilities such as campus network, multi-media teaching system; while soft environment mainly includes digital teaching resources as the core of the software environment, as well as the potential soft environment based on the policy environment and cultural environment. 


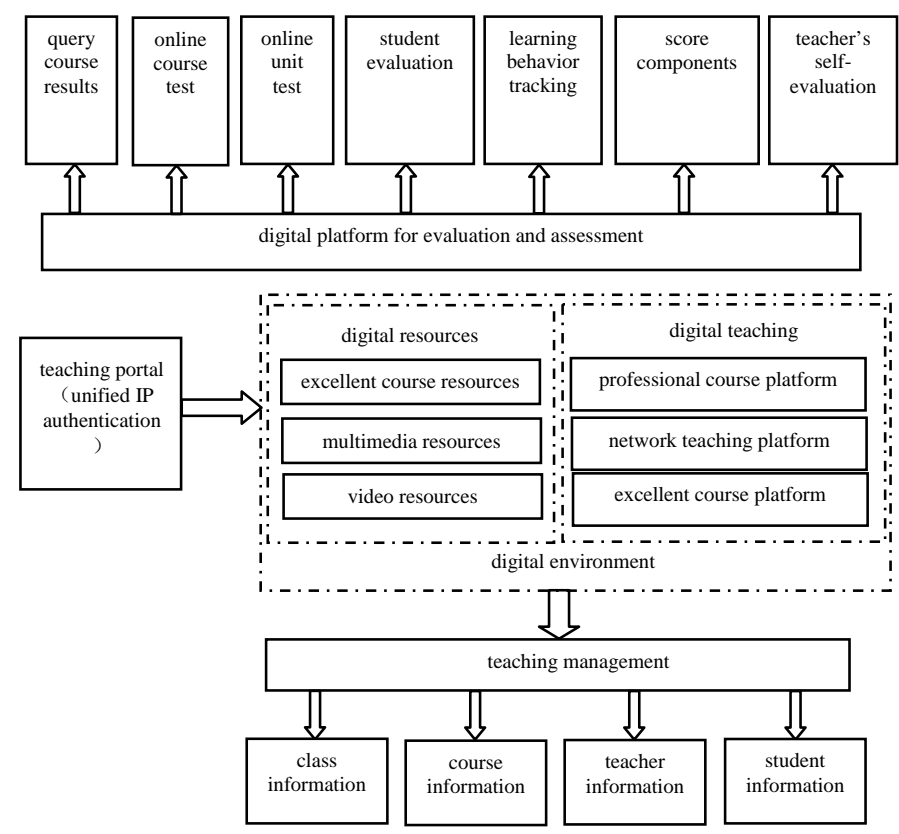

Figure 1. the structure of digital teaching platform

\section{1) The composition of hard environment}

Digital teaching hard environment is mainly consisted of hardware components supporting the digital teaching, including the campus network, multimedia projection classrooms, multimedia network classrooms, classrooms recording and broadcasting courses, digital library and so on.

a) Campus Network: It is the core of digital teaching hardware environment and the basis for supporting digital teaching platform. It is mainly made up of the servers, networking equipments and network transmission lines, etc. The basic function is to form the school's teaching, management and research services, users can share the variety of information resources within the campus network and the internet. Since campus network is the foundation of the digital learning environment, it is a prerequisite for campus network to have well-planned schemes, design and management in establishing the digital teaching environment. Construction of campus network must be combined with the school educational goals and highlight its teaching service and learning function.

b) Multimedia Projection Classrooms: They are mainly composed of a variety of media devices, including classroom projectors, video showcase, multimedia computer, DVD players, recorders, electric screen and the campus network interface. It is an important component of digital teaching environment. It is also the terminal platform for teachers, students and digital teaching environment to interact. With widespread distribution and efficient utilization, it has become the universities' current main classroom teaching environment.

c) Multimedia Network Classrooms: With a number of computers comprising a small local area network, realizing the communication between teachers and students through the network devices, multimedia network classrooms are the teaching systems with a variety of auxiliary management function [4]. In the multimedia network classroom, various forms of multimedia teaching can be carried out. Real-time interaction between teachers and students is an important functional characteristic. Network teaching can be easily carried out with multimedia network classrooms connecting to campus network. 
d) Classrooms Recording and Broadcasting excellent courses: They are the live and broadcast systems for real-time multimedia. As the anchor of the teaching sites for real-time video broadcasting, it can meet the needs of video conference and video teaching within the school's N-campus.

e) Digital Library: Running on high-speed broadband network, digital library is a distributed over a large-scale and crossing database searching of massive amounts of digital information resources library group. It is an important part of the construction for digital teaching environment, with convenient query, timely information, opening up resources, breaking time and space and efficient management, etc. Through the network, students can follow a variety of critical information to query library materials, which greatly improves the efficiency of information search and the utilization of library materials.

f) Other facilities: Other processing, transmission, use of digital teaching information facilities, such as digital language lab, virtual laboratories, digital learning resource center are the infrastructure to constitute a digital teaching hard environment.

\section{2) The composition of soft environment}

Beyond the hardware environment, soft environment is closely related to software and human factors. It is a more far-reaching part to constitute the digital teaching environment, which is also easily neglected.

a) Policy Environment: It is the pioneer in digital teaching environment and the primary factor to ensure that construction. Therefore, the highest political level and all levels of management of schools should pay attention to develop the digital teaching environment, make construction and development planning and design practical measures, with human resource and resource material support for digital teaching environment, to create a good environment for policy support.

b) Cultural Environment: It is mainly consisted of modern educational thoughts, ideas and consciousness of teachers and students, the capability of modern educational technology, digital teaching environment and learning atmosphere and so on. Lack of cultural environment is the biggest potential factor that has hindered the development and popularization of digital teaching, which is also the longest-term and the most arduous task to build digital teaching environment.

c) Software Environment : Software environment not only includes the application software and the operating system supporting the hardware, but more importantly includes a variety of digital teaching resources. Generally, the former synchronized with the hardware environment, is easier to achieve both in time and content. With abundant digital teaching resources, the educational advantage can be developed in the digital teaching environment. Therefore, digital teaching resources are the focus of software environmental construction, including multimedia material library, professional knowledge, courseware library, case library, library database, test database and so on.

\section{2 Resources}

It is far more enough to have the base platform, teaching resources must be vigorously carried out. The ultimate goal of digital campus teaching system is applications and services for teaching and research in schools. Our school not only introduces teaching resources, but also develops teaching resources of independent intellectual property rights based on the digestion and absorption to innovation. Educational information resources are the key and bottleneck to promote the applications of digital teaching system. In this area, human, material, financial resources and time are needed to be invested most. Only with a variety of educational and learning resources, digital teaching system can be used to conduct the teaching and learning activities. 


\section{3 Team construction}

- Firstly, the construction of digital teaching system is an important pillar to improve digital campus; the leaders of Secondary Colleges should focus on strengthening leadership and responsibility to carry out the school's digital teaching system construction smoothly.

- Secondly, the construction and application of teaching system is a system project that needs the close cooperation of various departments to function properly. So it is a good way to strengthen cooperation and increase investment that ensures the problem of system application to be solved.

- Finally, with the use of modern education technologies, teachers can improve teaching levels and quality. It is an important guarantee to realize the digital campus construction. The purpose of the teachers' teaching technological training is to promote the improvement of teaching ability by learning basic theory, basic skills training and practical demonstration of good teaching cases discuss and enhance teachers' initiative and consciousness of the application of modern education technology.

\section{4 Mechanism Construction}

The development and application of teaching resources are powerful factors, such as network teaching, multimedia courseware, three-dimensional (3D) courseware, teacher lecture videos and excellent courses to guarantee the digital university teaching as a new way to improve the teaching quality.

\section{1) Network Teaching Mechanism Construction}

According to the current university's actual situation, network teaching should be carried out by paying attention to the interaction between teachers and students, and the case of students participating in the course. Through school projects, to promote the extensive application of network teaching platform and to make the network teaching platform become an important means of accumulation teaching resources. To choose the excellent course from characteristic disciplines, and crucial course from better basis emerging disciplines, through project to support the course learning website of this kind of course. At regular intervals, completed multimedia courseware can be appraised and selected courseware can be funded in the follow-up support.

\section{2) Multimedia Courseware development mechanism construction}

Multimedia courseware development should be focused on the curriculum production for public basic courses. With the organization and planning of relevant divisions, the public basic courses should be sequentially planned in order to determine the form and means of media, and then make further labor division. Expert Group and Educational Technology Management Center should be organized to verify courses, design, develop and make appropriate policies, to form a unified planning, investment, management, design, development, test, feedback, modification, evaluation, promotion and so on. So it makes a solid basis for the future public basic courses to realize network teaching gradually, with the establishment of Multimedia teaching materials and courseware development mechanism.

\section{3) 3D Courseware mechanism construction}

Based on purchasing the completed production platform, the production of three-dimensional courseware demands teachers joining the training organized by Information Network Center and finishing the courseware independently.

\section{4) Online sharing of teaching video mechanism construction}

The lecture videos of national, provincial, university excellent teachers must be uploaded to sharing platform of teaching resources; the other teachers are encouraged to record their own video lectures and upload to a sharing platform. The school will give the appropriate incentives.

\section{5) Network courses mechanism construction}


Excellent courses must be implemented online teaching and teaching quality is excellent. The teachers, who apply for university level or above, should establish online course ahead of one year and interact with students through teaching platform and the effect is good.

Through the above mechanism and the conduct of online teaching, the initiative of student learning can be improved. Students will have the desire to learn independently, expand their learning horizons, enhance selfmanagement and make a good foundation to continue learning for the future.

\section{6) Teacher training mechanism construction}

The training focuses on young teachers to master and apply the modern education technology. It takes the advantages of modern education technology in teaching and improves teaching quality and efficiency. To strengthen the application of teacher education technology, it is necessary to establish the appropriate incentives and carry out extensive and comprehensive training for teachers and evaluation to stimulate the initiative of teachers to use appropriate software to develop their own multimedia courseware.

\section{Conclusions}

The construction of digital teaching system is an important initiative in China's higher education reform. In the process of the construction of the digital teaching system, the leader is the key, the management department is the core, technical department is the warranty, and the application effect of teachers and students is the goal. This paper highlights the problems in the digital teaching platform, and provides relative solutions by presenting the construction goal, analyzing the construction scheme and providing a reference in construction and promotion.

\section{References}

[1] Chengzhong Guo, "Development of China's Information Technology and Basic Ideas", http://www.ccid.net.2002.7.31. (in chinese)

[2] Zhixian Zhong, "E-Teaching Mode-Theory Construction and Illustration”, Beijing: Science Education Publishing Company, 2006, pp.6-8. (in chinese)

[3] Yongming Zhou, "Open Digital Design and Construction of Campus Network”, Microcomputer Applications, Vol 1, 2007. (in chinese)

[4] Wenlang Luo, "Modern Education Technology", Beijing: Beijing University of Aeronautics \& Astronautics Press, Aug. 2006. (in chinese) 